\title{
Sustained Morphine Exposure Induces a Spinal Dynorphin- Dependent Enhancement of Excitatory Transmitter Release from Primary Afferent Fibers
}

\author{
Luis R. Gardell, Ruizhong Wang, Shannon E. Burgess, Michael H. Ossipov, Todd W. Vanderah, \\ T. Philip Malan Jr, Josephine Lai, and Frank Porreca \\ Departments of Pharmacology and Anesthesiology, University of Arizona, Tucson, Arizona 85724
}

Paradoxical opioid-induced pain has been demonstrated repeatedly in humans and animals. The mechanisms of such pain are unknown but may relate to opioid-induced activation of descending pain facilitatory systems and enhanced expression and pronociceptive actions of spinal dynorphin. Here, the possibility that these opioid-induced central changes might mediate increased excitability to the spinal cord was tested. Tactile and thermal hypersensitivity was observed at 7 , but not 1 , days after subcutaneous morphine pellet implantation; placebo pellets produced no effects. Basal and capsaicin-evoked release of calcitonin gene-related peptide (CGRP) was measured in minced spinal tissues taken from naive rats or rats on postpellet days 1 and 7 . The content and evoked release of CGRP were significantly increased in tissues from morphine-exposed rats at 7 , but not 1 , days after implantation. Morphine increased spinal dynorphin content on day 7 in rats with sham bilateral lesions of the dorsolateral funiculus (DLF) but not in rats with
DLF lesions. Pharmacological application of dynorphin $A_{(2-13)}$, a non-opioid fragment, to tissues from naive rats enhanced the evoked release of CGRP. Enhanced evoked release of CGRP from morphine-pelleted rats was blocked by dynorphin antiserum or by previous lesions of the DLF. Sustained morphine induces plasticity in both primary afferents and spinal cord, including increased CGRP and dynorphin content. Morphineinduced elevation of spinal dynorphin content depends on descending influences and enhances stimulated CGRP release. Enhanced transmitter release may allow increased stimulusevoked spinal excitation, which is likely to be critical for opioidinduced paradoxical pain. Such pain may manifest behaviorally as antinociceptive tolerance.

Key words: opiate tolerance; opioid paradoxical pain; descending facilitation; spinal dynorphin; CGRP release; opioid trophic effects
It is well documented that morphine elicits paradoxical abnormal pain (i.e., hyperalgesia or enhanced nociception) in both clinical and preclinical settings. Abnormal pain has been described in patients after spinal morphine administered for chronic pain (Arner and Meyerson, 1988). Such abnormal pain differs in presentation, location, and quality than the original pain complaint (Ali, 1986; Stillman et al., 1987; De Conno et al., 1991; Devulder, 1997). Preclinical studies have also demonstrated opioid-induced abnormal pain (Yaksh et al., 1986; Yaksh and Harty, 1988; Mao et al., 1994, 1995c, 1998; Larcher et al., 1998; Celerier et al., 2000, 2001; Vanderah et al., 2000, 2001a,b). The mechanisms underlying such pain are unknown. Recent investigations have demonstrated that morphine-evoked abnormal pain may result from neuroplastic changes in the rostral ventromedial medulla (RVM) (Vanderah et al., 2001b). The RVM has been identified as a source of spinopetal inhibitory and facilitatory modulation of nociceptive inputs (Heinricher et al., 1989; Fields, 1992; Morgan et al., 1992). Manipulations performed in the RVM that block its activity are known to block pain in a number of settings, including inflammation (Mansikka and Pertovaara, 1997) and nerve injury (Kovelowski et al., 2000; Burgess et al., 2002). Hyperalgesia resulting from naloxone-precipitated opioid withdrawal was

\footnotetext{
Received March 26, 2002; revised May 2, 2002; accepted May 10, 2002.

This work was supported by National Institutes of Health Grant DA 12656.

Correspondence should be addressed to Dr. Frank Porreca, Department of Pharmacology, College of Medicine, University of Arizona Health Sciences Center, Tucson, AZ 85724. E-mail: frankp@u.arizona.edu.

Copyright (C) 2002 Society for Neuroscience $0270-6474 / 02 / 226747-09 \$ 15.00 / 0$
}

blocked by RVM lidocaine (Kaplan and Fields, 1991) and associated with increased discharge of cells thought to mediate facilitation (i.e., "ON" cells) (Bederson et al., 1990; Kim et al., 1990).

Similarly, tactile and thermal hypersensitivity resulting from sustained delivery of subcutaneous morphine was abolished by RVM microinjection of lidocaine or by bilateral lesions of the dorsolateral funiculus (DLF), suggesting the importance of descending facilitatory influences in opioid-induced abnormal pain (Vanderah et al., 2001b). Manipulations that blocked opioidinduced pain also blocked the behavioral manifestation of opioid antinociceptive tolerance. Opioid-induced abnormal pain and antinociceptive tolerance are also characterized by an upregulation in spinal dynorphin content (Vanderah et al., 2000). Spinal administration of dynorphin has been shown to induce pain (Vanderah et al., 1996; Laughlin et al., 1997), and spinal (+)-5methyl-10,11-dihydro-5H-dibenzo [a,d] cyclohepten-5,10-imine maleate (MK-801) or dynorphin antiserum blocks morphineinduced abnormal pain and antinociceptive tolerance (Vanderah et al., 2000; Gardell et al., 2001). These studies suggest a pronociceptive role for upregulated spinal dynorphin as a mediator of opioid-induced pain.

Morphine-induced abnormal pain and antinociceptive tolerance is known to be blocked by NMDA receptor antagonists (Mao et al., 1995a,c; Larcher et al., 1998; Celerier et al., 1999; Laulin et al., 1999). Although a common interpretation of these findings is an interaction between opioid and NMDA receptors via intracellular mechanisms (Mao et al., 1995b,c,d), an alternative possibility might be the blockade of opioid-induced excita- 
tion. However, the source of possible opioid-induced excitation is not known. Recently, Hargreaves and colleagues suggested that non-opioid fragments of dynorphin can enhance the evoked release of calcitonin gene-related peptide (CGRP) in isolated spinal cord tissues (Claude et al., 1999). The present study was undertaken to test the hypothesis that the upregulation of spinal dynorphin resulting from sustained morphine exposure acts to enhance the evoked release of an excitatory transmitter from primary afferent fibers. Additionally, the possible relationship between opioid-induced descending facilitation and spinal dynorphin was explored.

\section{MATERIALS AND METHODS}

Male Sprague Dawley rats (Harlan Sprague Dawley, Indianapolis, IN), 200-300 gm at time of testing, were maintained in a climate-controlled room on a $12 \mathrm{hr}$ light/dark cycle (lights on at 6:00 A.M.) with food and water available ad libitum. All testing was performed in accordance with the policies and recommendations of the International Association for the Study of Pain and the National Institutes of Health guidelines for the handling and use of laboratory animals and received approval from the Institutional Animal Care and Use Committee of the University of Arizona. Groups of 5-10 rats were used in all experiments.

Sustained morphine administration. The sustained systemic administration of morphine was accomplished by subcutaneous implantation of two $75 \mathrm{mg}$ free base pellets. Control groups received placebo pellets containing excipient only. The pellets were obtained as a generous gift from the National Institute on Drug Abuse Drug Supply Program.

Behavioral thresholds. Behavioral responses to thermal and tactile stimuli were determined before implantation of the pellets and on the first or seventh day of pellet exposure (i.e., with the pellets in place) to establish the possible presence of changes in tactile and thermal response thresholds. The method of Hargreaves et al. (1988) was used to assess paw-withdrawal latency to a thermal nociceptive stimulus. Rats were allowed to acclimate within a Plexiglas enclosure on a clear glass plate maintained at $30^{\circ} \mathrm{C}$. A radiant heat source (i.e., high-intensity projector lamp) was activated with a timer and focused onto the plantar surface of the hindpaw. Paw-withdrawal latency was determined by a motion detector that halted both lamp and timer when the paw was withdrawn. A maximal cutoff of $40 \mathrm{sec}$ was used to prevent tissue damage. A significant reduction in paw-withdrawal latency from the pre-pellet value was interpreted as thermal hyperalgesia. Pairwise comparisons were performed with Student's $t$ test, and significance was set at $p \leq 0.05$.

The paw-withdrawal thresholds of the hindpaws of the rats were determined in response to probing with eight calibrated von Frey filaments (Stoelting, Wood Dale, IL) in logarithmically spaced increments ranging from 0.41 to $15 \mathrm{gm}(4-150 \mathrm{mN})$. Each filament was applied perpendicularly to the plantar surface of the paw of rats kept in suspended wire-mesh cages. Withdrawal threshold was determined by sequentially increasing and decreasing the stimulus strength ("up and down" method), analyzed using a Dixon nonparametric test (Dixon, 1980; Chaplan et al., 1994), and expressed as the mean withdrawal threshold. A significant reduction in paw-withdrawal threshold from the pre-pellet value indicated tactile hypersensitivity. Pairwise comparisons were performed with Student's $t$ test. Significance was set at $p \leq 0.05$.

Spinal DLF lesions. Bilateral spinal lesions at the $\mathrm{T}_{8}$ level were performed in naive rats under halothane anesthesia. A laminectomy was made at the $\mathrm{T}_{8}$ level to expose the spinal cord. Lesions of the dorsolateral funiculus (DLF) were performed by crushing the area with fine forceps under a dissecting microscope. Sham-DLF surgery was performed by exposing the vertebrae and performing the laminectomy but without cutting neuronal tissue. Hemostasis was confirmed, and the wound over the exposed spinal cord was packed with Gelfoam and closed. All lesions were verified histologically at the termination of the experiment. Only rats with appropriately placed DLF lesions, determined post hoc, were included in the subsequent data analysis.

Tissue extraction and preparation. Rats were deeply anesthetized with halothane and decapitated. The spinal column was cut through at the pelvic girdle. Hydraulic extrusion was performed by inserting a 16 gauge needle into the sacral vertebral canal and expelling with ice-cold saline. The spinal cord was immediately placed on ice in a glass Petri dish, and the dorsal half of the lumbar cord was dissected. Tissue samples that were to be quantified for dynorphin content were then immediately frozen in liquid nitrogen and stored at $-70^{\circ} \mathrm{C}$ until assayed. Tissues for use in the CGRP release assay were weighed and chopped into $0.2 \mathrm{~mm}$ cubes with a McIlwain tissue chopper (Mickle Laboratory Engineering, Gomshall, UK).

CGRP release assays. Minced tissue samples were placed in a $1 \mathrm{cc}$ chamber and continuously superfused with oxygenated modified Krebs' buffer (135 mM NaCl, $3.5 \mathrm{~mm} \mathrm{KCl}, 1 \mathrm{mM} \mathrm{MgCl}_{2}, 20 \mathrm{~mm} \mathrm{NaHCO}_{3}, 1 \mathrm{~mm}$ $\mathrm{NaHPO}_{4}, 2.5 \mathrm{~mm} \mathrm{CaCl}_{2}, 3.3 \mathrm{~mm}$ dextrose, $0.1 \mathrm{~mm}$ ascorbic acid, $10 \mathrm{~mm}$ thiorphan, and $0.1 \%$ bovine serum albumin) maintained at $37^{\circ} \mathrm{C}, \mathrm{pH} 7.4$, at a rate of $0.5 \mathrm{ml} / \mathrm{min}$ with a Brandel Superfusion Pump (Brandel, Gaithersburg, MD). The tissue was allowed to equilibrate for $45 \mathrm{~min}$. Superfusate was collected in $3 \mathrm{~min}$ intervals into test tubes using a fraction collector (Gilson, Middleton, WI). A total of four to five fractions (12-15 $\mathrm{min}$ ) were collected before adding capsaicin. Capsaicin was then added for a perfusion concentration of $1 \mu \mathrm{M}$ for $6 \mathrm{~min}$ (two fractions). Superfusate was then collected for an additional $27-30 \mathrm{~min}$ (9-10 fractions).

Radioimmunoassay for CGRP in superfusate. The superfusate obtained from the release assay was preincubated with $100 \mu \mathrm{l}$ of a C-terminally directed anti-CGRP antibody (generously donated by Dr. Michael Iadarola, National Institutes of Dental and Craniofacial Research, National Institutes of Health, Bethesda, MD) for $24 \mathrm{hr}$ at $4^{\circ} \mathrm{C}$. The samples were each mixed with $100 \mu \mathrm{l}$ of $\left[{ }^{125} \mathrm{I}^{\left.-T_{y r}{ }^{0}\right] \mathrm{CGRP}_{28-37}}\right.$ (at 20,000-25,000 cpm per assay tube) and $50 \mu$ l of goat anti-rabbit antiserum coupled to ferric beads and incubated for an additional $24 \mathrm{hr}$. The [ $\left.{ }^{125} \mathrm{I}\right] \mathrm{CGRP}$ bound to the CGRP antibody was separated from the free tracer through immunomagnetic separation (PerSeptive Diagnostics, Cambridge, MA). The immunoprecipitates were determined by gamma counting. Standard curves were generated, and CGRP content was determined through logit-log analysis. This assay has a minimal detection limit of $1-3 \mathrm{fmol} /$ tube. The CGRP antiserum used in these experiments binds near the $\mathrm{C}$-terminal end of CGRP and does not cross-react with cholecystokinin, neuropeptide $\mathrm{Y}$, or other peptides with similar $\mathrm{C}$-terminal residues. The CGRP concentrations were plotted against time in 3 min intervals. Evoked release was calculated as the total amount of CGRP released (i.e., CGRP-IR) during the capsaicin infusion above the basal release of CGRP.

Total CGRP content. Tissues were placed in $2 \mathrm{ml}$ of $0.01 \mathrm{~N} \mathrm{HCl}$ and homogenized using a Polytron, followed by centrif ugation at $2500 \times g$ for 20 min. The supernatant was diluted 1:400 in modified Krebs' buffer and then assayed for total CGRP content using the radioimmunoassay described above. Pairwise comparisons between treatments were detected using Student's $t$ test. Significance was determined at the $p \leq 0.05$ level.

Dynorphin immunoassay. Tissues were placed in $1 \mathrm{~N}$ acetic acid and homogenized with a Polytron. The homogenates were incubated for 30 $\min$ at $95^{\circ} \mathrm{C}$ and centrifuged at $14,000 \times g$ for $20 \mathrm{~min}\left(4^{\circ} \mathrm{C}\right)$. The supernatants were lyophilized and stored at $-70^{\circ} \mathrm{C}$. Protein concentrations were determined using the bichinchoninic acid method with bovine serum albumin as a standard. Immunoassay was performed using a commercial enzyme immunoassay system for dynorphin $\mathrm{A}_{(1-17)}$ (Bachem/Peninsula Labs, Torrance, CA). Standard curves were constructed using the software Prizm (GraphPad, San Diego, CA). Pairwise comparisons between treatments were detected using Student's $t$ test. Significance was determined at the $p \leq 0.05$ level.

Dynorphin antiserum. The anti-dynorphin antiserum that was used to neutralize dynorphin in the release experiments was raised against dynorphin $\mathrm{A}_{(1-13)}$ (item \#T-4278.0500; Bachem/Peninsula Labs). This antiserum demonstrates $100 \%$ cross-reactivity with dynorphin $\mathrm{A}_{(1-17)}$ and dynorphin $A_{(1-12)}$ fragments. Control serum refers to serum from rabbits that have not been exposed the antigen.

Immunofluorescence. After the anesthesia with ketamine $\mathrm{HCl} /$ xylazine $(1 \mathrm{ml} / \mathrm{kg}$; Sigma; St. Louis, MO), the rats were perfused transcardially with $0.1 \mathrm{M}$ PBS until the exudate ran clear and fixed with $10 \%$ formalin and $0.05 \%$ glutaraldehyde in $0.1 \mathrm{M}$ PBS, $\mathrm{pH} 7.4$, for $\sim 15 \mathrm{~min}$. Lumbar spinal cords were harvested and postfixed in $10 \%$ formalin overnight and cryoprotected with $20 \%$ sucrose in $0.1 \mathrm{M}$ PBS. Frozen frontal sections $(20$ $\mu \mathrm{m})$ were washed in $0.1 \mathrm{M}$ PBS and then incubated with a rabbit anti-CGRP antiserum (1:40,000; Bachem/Peninsula Labs) in $0.1 \mathrm{M}$ PBS with $5 \%$ normal goat serum overnight at $4{ }^{\circ} \mathrm{C}$, followed by washing and secondary incubation with a Cy3-conjugated goat anti-rabbit $\operatorname{IgG}(1: 500$; Jackson ImmunoResearch, West Grove, PA) for $2 \mathrm{hr}$. The sections were rinsed and mounted in Vectashield. Fluorescence digital images were captured using a Nikon (Tokyo, Japan) E800 fluorescence microscope outfitted with a Hamamatsu (Bridgewater, NJ) C5810 color CCD camera that output to a Pentium microcomputer. 


\section{RESULTS}

\section{Evaluation of tactile and thermal thresholds after placebo or morphine pellets}

The mean pretreatment (i.e., baseline) paw-withdrawal threshold to probing of the hindpaw with von Frey filaments was $15 \pm 0 \mathrm{gm}$, and the paw-withdrawal latency to noxious radiant heat applied to the plantar aspect of the hindpaw was $20.8 \pm 0.26 \mathrm{sec}$. Rats with morphine pellets demonstrated a significantly reduced mean pawwithdrawal threshold of $4.53 \pm 0.74 \mathrm{gm}(p \leq 0.05) 7 \mathrm{~d}$ after pellet implantation. Similarly, these animals also showed a significant reduction in the mean paw-withdrawal latency of $13.9 \pm 1.02 \mathrm{sec}$ $(p \leq 0.05)$. Previous studies have shown that the development of tactile and thermal hypersensitivity after morphine pellet implantation is time related. Vanderah et al. (2001) showed that the response thresholds to tactile and thermal stimulation were modestly reduced from pretreatment values within $1 \mathrm{~d}$ after morphine exposure but did not achieve a maximal level of change until day 7. In the present studies, the paw-withdrawal threshold was reduced from a baseline of $15.0 \pm 0$ to $13.1 \pm 1.4 \mathrm{gm}$ at day 1 after morphine pellets. Similarly, paw-withdrawal latencies were essentially unchanged with baseline values of $21.0 \pm 0.6$ and $20.15 \pm$ $0.6 \mathrm{sec}$ at day 1 after morphine pellets. These tactile and thermal threshold values at day 1 post-morphine pellets were not significantly different from the pre-pellet baseline $(p>0.05$; Student's $t$ test). In control rats that received placebo pellets, the mean paw-withdrawal threshold $(15 \pm 0$ and $14.5 \pm 0.5 \mathrm{gm}$ at 1 and $7 \mathrm{~d}$, respectively), and the mean paw-withdrawal latency $(21.2 \pm 0.51$ and $20.6 \pm 0.66 \mathrm{sec}$ at 1 and $7 \mathrm{~d}$, respectively) were not significantly different from the respective pre-pellet values $(p>0.05)$. These results suggest that exposure to subcutaneous morphine pellets elicits enhanced pain that is firmly established by postpellet day 7, with earlier time points likely representing a timerelated transitional period of sensory thresholds (Vanderah et al., 2001).

\section{Morphine-induced upregulation of spinal dynorphin-IR is blocked by DLF lesions}

Rats were prepared with bilateral DLF, or sham-DLF, lesions and were implanted with either placebo or morphine pellets $2 \mathrm{~d}$ after the surgical procedures. On the seventh day after pellet implantation, the dorsal halves of the lumbar spinal cords were removed and assayed for dynorphin content. The sustained exposure to morphine in rats with sham-DLF lesions produced a significantly greater $(p \leq 0.05)$ spinal dynorphin content relative to the placebo-pelleted control group (Fig. 1). The dynorphin-IR levels were $384 \pm 18$ and $296 \pm 12 \mathrm{fmol} / \mathrm{mg}$ protein in the morphine- and placebo-treated sham-DLF groups, respectively (Fig. 1). In rats that had bilateral DLF lesions before morphine pellet implantation, however, the dynorphin level was $292 \pm 8$ $\mathrm{fmol} / \mathrm{mg}$ protein, which was not significantly different $(p>0.05)$ from that of the placebo-pelleted, sham-lesioned control group (Fig. 1). Lesions of the DLF alone did not alter spinal dynorphin expression. Rats implanted with placebo pellets that also received DLF lesion had a mean dynorphin content of $282 \pm 8 \mathrm{fmol} / \mathrm{mg}$ protein, which was not significantly different $(p>0.05)$ from that of the placebo-pelleted, sham-lesioned control group (Fig. 1). Thus, sustained morphine exposure induced an enhanced level of spinal dynorphin-IR that could be prevented by bilateral lesion of the DLF.

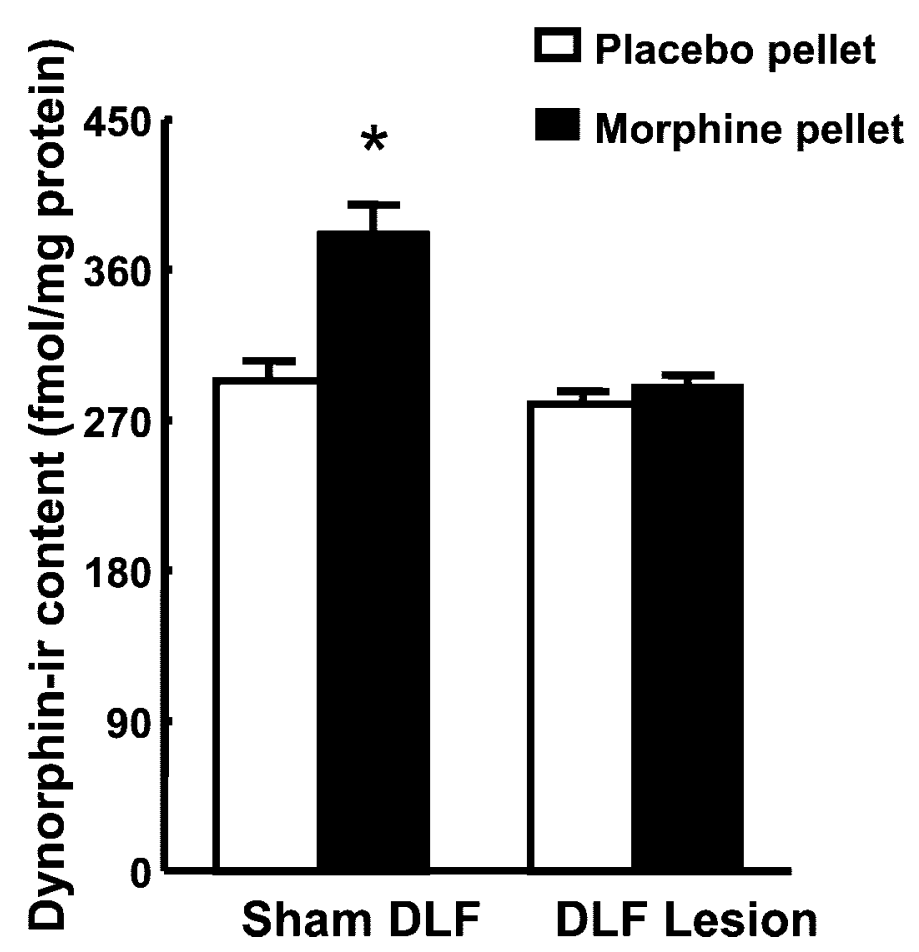

Figure 1. Male Sprague Dawley rats received bilateral lesions of the DLF or sham surgery at $T_{8}$ and were allowed to recover for $2 \mathrm{~d}$. The animals were then implanted with two subcutaneous placebo or morphine ( $75 \mathrm{mg}$ ) pellets. After $7 \mathrm{~d}$, the spinal cords were removed, and the dorsal halves of the lumbar cords were assayed for dynorphin immunoreactivity. The dorsal lumbar cords of rats with morphine pellets and sham-DLF lesions showed significantly greater levels of dynorphin $\left({ }^{*} p \leq 0.05\right)$ than tissues from rats with placebo pellets and sham-DLF lesions. The levels of spinal dynorphin from the rats with placebo pellets and DLF lesions were not different from those seen in tissues from rats with placebo pellets and sham-DLF lesion $(p>0.5)$. Morphine pellets failed to significantly increase the levels of dynorphin in spinal tissues taken from animals with DLF lesions. These levels were not different from those seen with placebo pellets and DLF lesion or from placebo pellets and sham-DLF lesion. Each treatment group consisted of six animals.

\section{Sustained morphine exposure enhances CGRP content}

Sustained morphine exposure also produced an upregulation of immunoreactivity for CGRP in the lumbar dorsal horn of the spinal cord (Fig. 2) in a time-dependent manner. Enhanced fluorescence labeling for CGRP was seen in the dorsal horn $7 \mathrm{~d}$ (Fig. 2D), but not $1 \mathrm{~d}$ (Fig. $2 B$ ), after morphine pellet implantation when compared with that seen in tissues from placebopelleted rats at post-implantation days 1 and 7 (Fig. $2 A, C$, respectively) (preabsorbed control not shown). CGRP was confined bilaterally to the outer laminas (I and II) of the spinal dorsal horn in placebo rats and rats that were exposed to morphine for $1 \mathrm{~d}$ (Fig. 2A-C). Tissues taken from rats after $7 \mathrm{~d}$ of morphine pellet implantation, however, showed that the CGRP was more intense in the outer laminas of the dorsal horn, and the immunolabeling could be seen to extend into deeper laminas (Fig. 2D).

CGRP in the dorsal horn was quantified by radioimmunoassay of spinal cord extracts in separate parallel assays from placeboand morphine-pelleted rats after day 1 , and again after day 7 , of pellet implantation. CGRP content was determined to be $1120 \pm$ 58 and $1336 \pm 81 \mathrm{pmol} / \mathrm{gm}$ tissue in spinal tissues from $1 \mathrm{~d}$ placebo- and morphine-pelleted rats, respectively $(n=6$ rats per group). When compared with the day 1 placebo-pelleted control group, the morphine-pelleted group on day 1 showed a $19 \pm 7.5 \%$ 

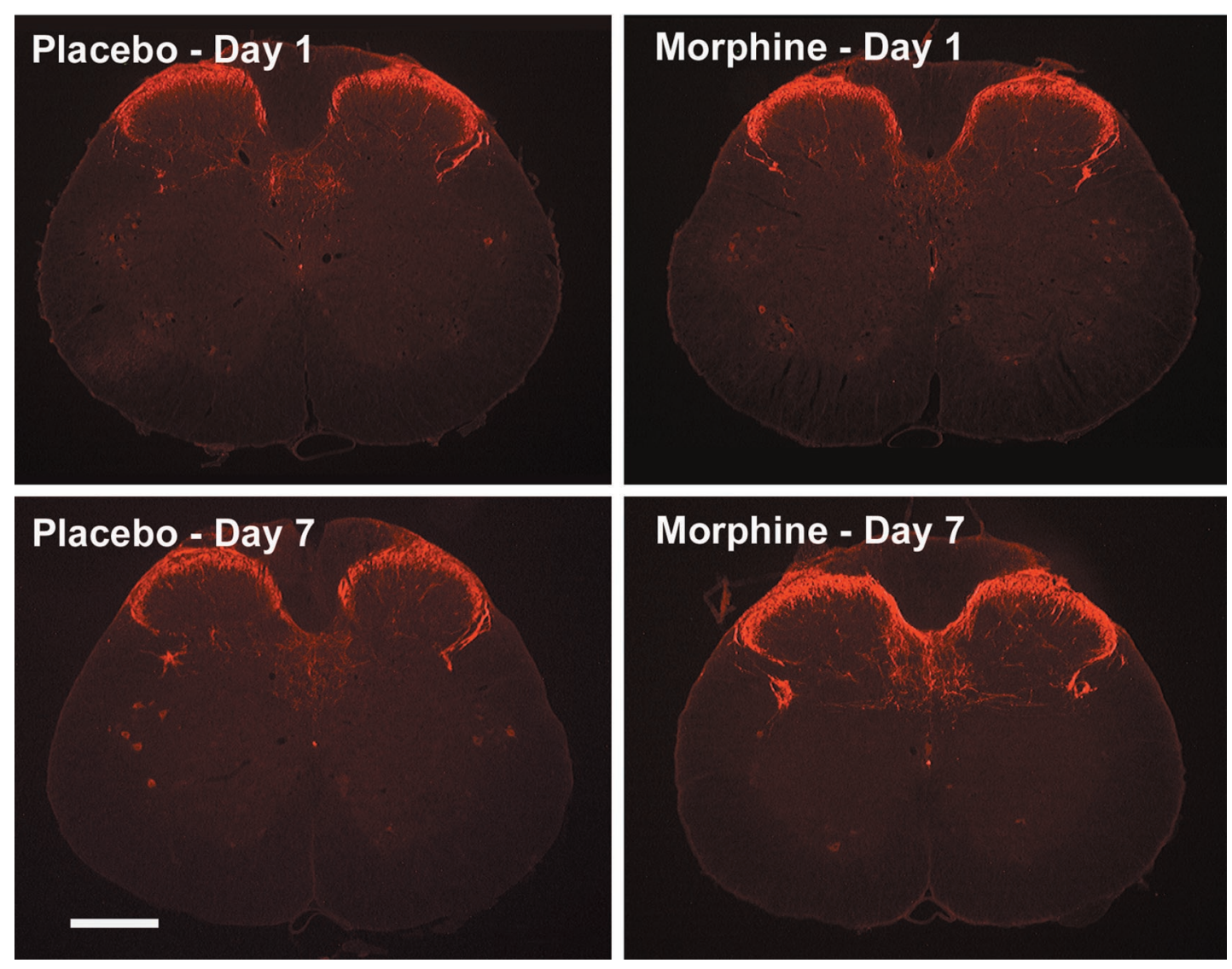

Figure 2. CGRP immunoreactivity in the spinal cord at approximately L5. Tissue from placebo-treated rats is shown in the left column, and that from morphine-treated rats is shown in the right column. No apparent difference in CGRP immunoreactivity is seen between the spinal sections obtained from placebo-treated and morphine-treated rats $1 \mathrm{~d}$ after pellet implantation. The staining intensity of CGRP in tissues from morphine-treated rats on day 7 is enhanced when compared with the placebo-treated rats on day 7. The enhanced staining is apparent in both laminas I/II and in deeper laminas. Scale bar, $400 \mu \mathrm{m}$.

increase in CGRP; this difference was small but statistically significant $(p \leq 0.05)$. CGRP content was determined to be $2455 \pm 309$ and $6451 \pm 595 \mathrm{pmol} / \mathrm{gm}$ tissue in spinal tissues from $7 \mathrm{~d}$ placebo- and morphine-pelleted rats, respectively $(n=8$ rats per group). When compared with the $7 \mathrm{~d}$ placebo-pelleted control group, the morphine-pelleted group on day 7 showed a $163 \pm$ $24 \%$ increase in CGRP, a difference that was statistically significant $(p \leq 0.05)$. These data are in good agreement with the immunohistochemical analysis of CGRP after 1 or $7 \mathrm{~d}$ of morphine exposure.

\section{Sustained morphine exposure enhances capsaicin- evoked, but not basal, release of CGRP}

Basal CGRP release was measured in tissues taken from rats 1 or $7 \mathrm{~d}$ after implantation of placebo or morphine pellets. No differences were observed in unstimulated release in these groups (Fig. $3 A$ ). Capsaicin-stimulated release of CGRP in tissues taken from rats $1 \mathrm{~d}$ after placebo pellets did not differ significantly from that observed in tissues taken from rats $7 \mathrm{~d}$ after placebo pellets (Fig. $3 A, B)$. Similarly, the capsaicin-stimulated release of CGRP observed in tissues taken from rats $1 \mathrm{~d}$ after morphine pellets did not differ significantly from that observed from tissue taken from placebo-pelleted rats at either time point (Fig. $3 A, B$ ). In contrast, capsaicin-evoked release of CGRP in tissues taken from rats $7 \mathrm{~d}$ after morphine pellets was significantly greater than that seen in either the placebo- or morphine-pelleted day 1 tissues (Fig.
$3 A, B)$. For comparison purposes, evoked post-placebo pellet day 1 CGRP release was normalized as $100 \pm 27 \%$. Under the same conditions, the evoked CGRP released from spinal dorsal horn tissue harvested $1 \mathrm{~d}$ after morphine pellet implantation was $112 \pm$ $38 \%$ of this control group (difference not significant). Similarly, evoked post-placebo pellet day 7 CGRP was normalized as $100 \pm$ $31 \%$. Under the same conditions, the evoked CGRP released from spinal dorsal horn tissues harvested $7 \mathrm{~d}$ after morphine pellets was $270 \pm 49 \%$ of this control $(p \leq 0.05)$.

\section{Enhanced evoked released CGRP in tissues from morphine-exposed rats is blocked by previous bilateral DLF lesions}

Tissues were taken $7 \mathrm{~d}$ after placebo or morphine pellet implantation from rats with previous sham-DLF or DLF lesions for evaluation of basal and evoked CGRP release. No differences were observed in unstimulated release in these groups (Fig. 4A). Capsaicin-stimulated release of CGRP in tissues from placebopelleted sham-DLF rats did not differ significantly from that observed in tissues from placebo-pelleted DLF rats (Fig. 4A). Evoked CGRP release in tissues taken from sham-DLF morphine-pelleted rats was significantly higher than that observed from tissues from either of the placebo-pelleted groups ( $p \leq$ 0.05 ) (Fig. 4B). In contrast, evoked CGRP release in tissues taken from DLF morphine-pelleted rats was not significantly different from that observed in tissues from the placebo-pelleted groups 
A

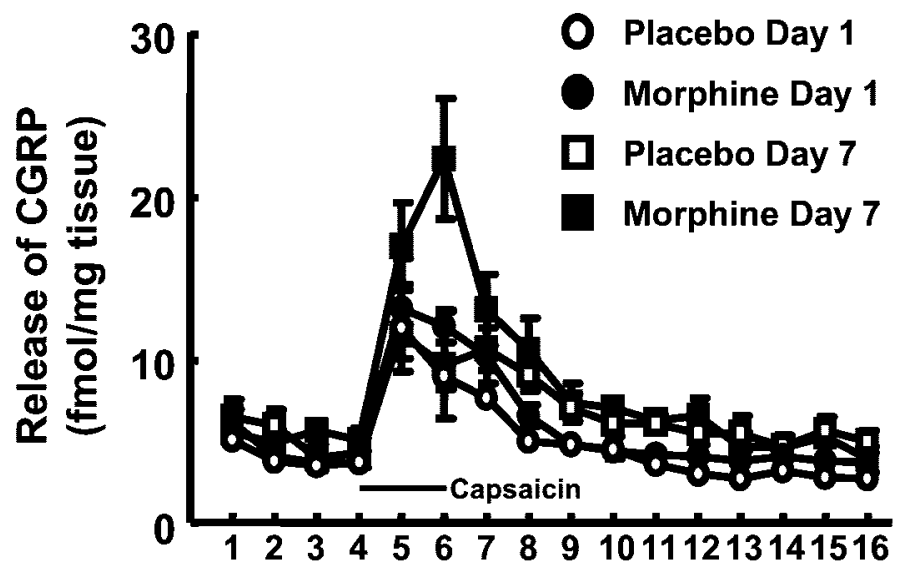

B

Fraction number ( 3 min intervals)

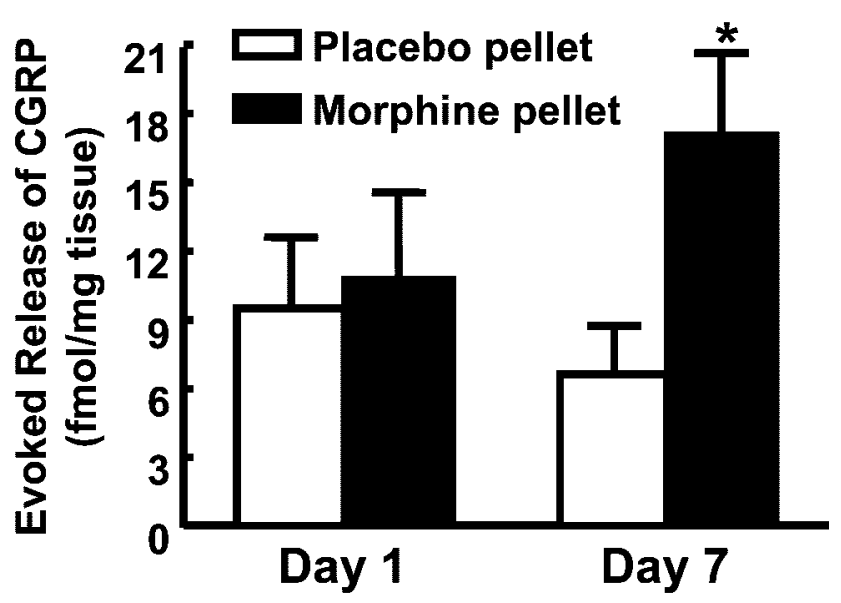

Figure 3. Male Sprague Dawley rats were implanted with two placebo pellets or morphine pellets. Separate groups were killed 1 and $7 \mathrm{~d}$ after pellet implantation, and dorsal lumbar spinal cord tissues were isolated, minced, and placed in perfusion chambers. $A$ shows the basal and evoked CGRP in the perfusate collected at 3 min intervals. The horizontal bar represents the period in which capsaicin $(1 \mu \mathrm{M})$ was added to the perfusate to evoke CGRP release. The capsaicin-evoked release of CGRP from the spinal tissues in vitro is demonstrated in $B$ and represents the amount of CGRP above the baseline release for each individual group. Basal levels of CGRP release did not differ among the treatment groups. Evoked CGRP release was not different between tissues from placebo- and morphine-treated groups at day 1 after pellet implantation $(p>0.5)$. However, tissues from the $7 \mathrm{~d}$ morphine-treated group showed a significantly greater level of capsaicin-evoked release of CGRP $\left({ }^{*} p \leq 0.05\right)$. Each treatment group consisted of six animals.

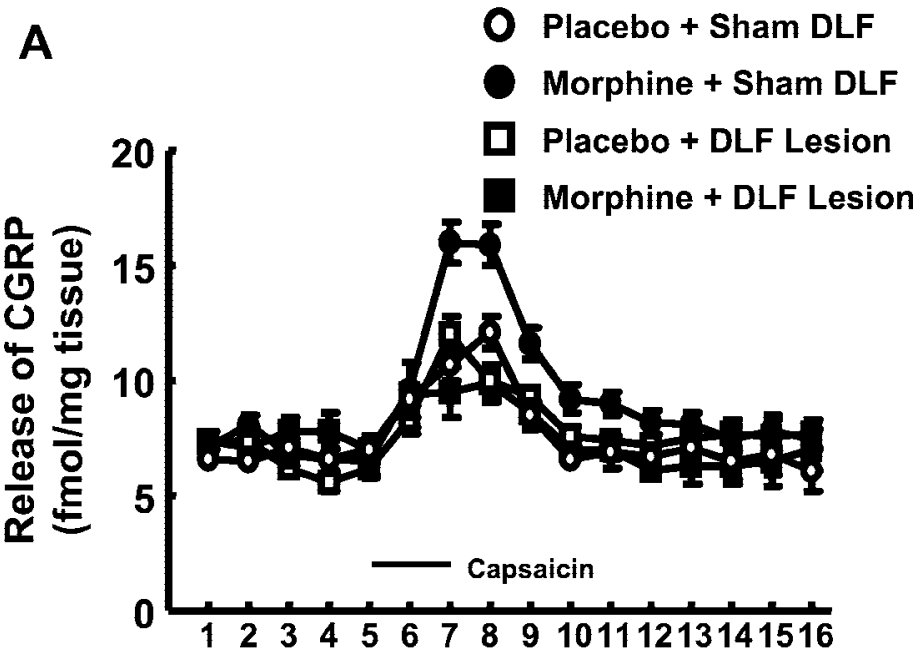

Fraction number (3 min intervals)
B

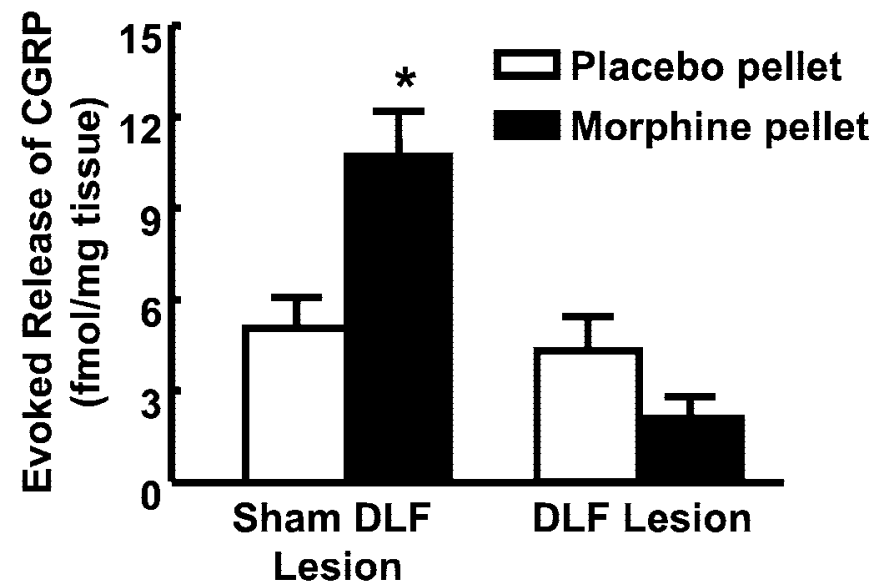

Figure 4. Male Sprague Dawley rats received bilateral lesions of the DLF or sham surgery at T8 and were allowed to recover for $2 \mathrm{~d}$. The animals were then implanted with two subcutaneous placebo or morphine $(75 \mathrm{mg})$ pellets. Seven days after pellet implantation, the spinal cords were removed, and the dorsal halves of the lumbar cords were assayed for basal and evoked CGRP release. The horizontal bar in $A$ represents the period in which capsaicin $(1 \mu \mathrm{M})$ was added to the perfusate to evoke the release of CGRP. Basal CGRP release was not different among the treatment groups. In tissues from the sham-DLF-lesioned and morphine-treated rats $(n=11)$, capsaicin-evoked release of CGRP was significantly $\left({ }^{*} p \leq 0.05\right)$ greater when compared with the sham-DLF, placebo-treated group $(n=11)$. Tissues from rats with DLF lesion and placebo pellets $(n=10)$ did not show significantly different levels of evoked CGRP release when compared with tissues from sham-DLF and placebo pellets. However, tissues from rats with bilateral DLF lesion and morphine pellets $(n=8)$ showed levels of evoked CGRP that were not significantly different from the DLF-lesioned placebo group or the sham-DLF-lesioned placebo group.

and was significantly lower than that seen in tissues from the sham-DLF morphine-pelleted group $(p \leq 0.05)$ (Fig. $4 B$ ). For comparison purposes, evoked CGRP release in sham-DLF placebo-pelleted tissues was normalized as $100 \pm 20 \%$. The evoked CGRP release in sham-DLF morphine-pelleted tissues was $210 \pm 28 \%$ of this control group ( $p \leq 0.05)$. Similarly, evoked CGRP release in DLF placebo-pelleted tissues was normalized as $100 \pm 25 \%$. The evoked CGRP release in DLF morphinepelleted tissues was $78 \pm 16$ of this control group (difference not significant). 


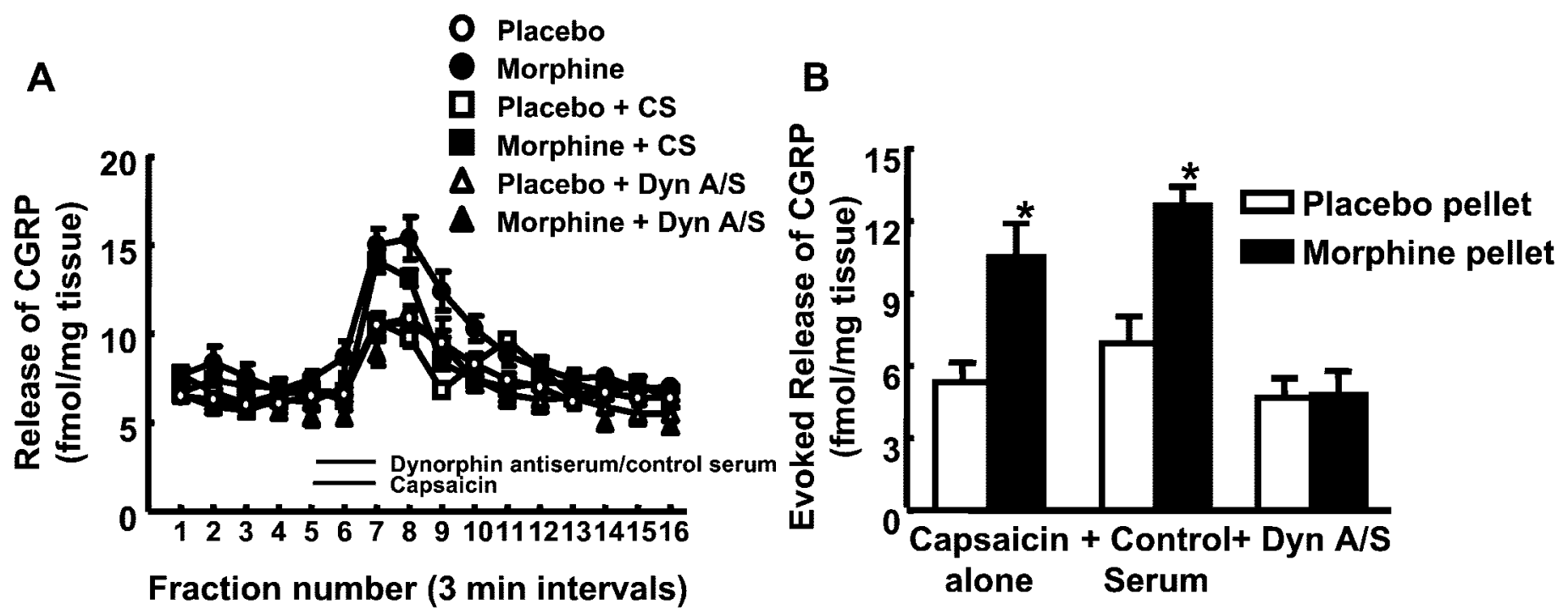

Figure 5. Male Sprague Dawley rats were implanted with two subcutaneous placebo or morphine pellets and killed $7 \mathrm{~d}$ after pellet implantation. The dorsal lumbar spinal cord tissue was dissected, minced, and placed in perfusion chambers. Basal and evoked CGRP released into the perfusate was measured at 3 min intervals $(A)$, and capsaicin-evoked CGRP release was indicated by the amount of CGRP present above the baseline release levels (B). The horizontal bars in $A$ represents the period in which capsaicin $(1 \mu \mathrm{M})$ and dynorphin antiserum $(1 \mathrm{mg} / 100 \mathrm{ml})(D y n A / S)$ or a rabbit control serum $(1 \mathrm{mg} / 100 \mathrm{ml})$ were added to the perfusate. Basal levels of CGRP release were not significantly different among the treatment groups. In separate experiments, neither dynorphin antiserum nor control serum $(C S)$ altered basal CGRP release (data not shown). Capsaicin-evoked release of CGRP was significantly greater in tissues from morphine-treated rats $7 \mathrm{~d}$ after pellet implantation when compared with the placebo-treated group ( $p \leq 0.05)$. Coadministration of capsaicin and control serum to the perfusion medium did not alter the capsaicin-evoked release of CGRP from tissues obtained from either placebo or morphine-treated rats; evoked CGRP release in the morphine-treated tissues was significantly greater than that seen in the placebo-pelleted group. Coadministration of capsaicin and a dynorphin antiserum to the perfusion medium prevented the enhanced capsaicin-evoked release of CGRP in tissues from morphine-treated rats such that the level of release was not different from the placebo control group. Each treatment group consisted of 10 animals.

\section{Enhanced capsaicin-evoked released CGRP in tissues from morphine-exposed rats is blocked by anti-dynorphin antiserum}

Neither control serum nor anti-dynorphin antiserum $(1 \mathrm{mg} / 100$ $\mathrm{ml})$ produced any change in basal release of CGRP in tissues taken $7 \mathrm{~d}$ after placebo or morphine pellets $(n=10$ per group; data not shown). As noted previously, no differences were observed in unstimulated CGRP release in tissues taken $7 \mathrm{~d}$ after placebo or morphine pellet implantation (Fig. 5A). Evoked CGRP release in tissues taken from placebo-pelleted rats did not differ significantly from that observed from tissues taken from placebo-pelleted rats in the presence of control serum or dynorphin antiserum (Fig. 5A). Evoked CGRP release in tissues taken from morphine-pelleted rats did not differ significantly from that observed in tissues taken from morphine-pelleted rats in the presence of control serum (Fig. $5 \mathrm{~A}$ ), but evoked release in both of these groups was significantly greater than that observed in the placebo-pelleted groups in the absence or presence of control serum. In contrast, evoked CGRP release in tissues taken from morphine-pelleted rats in the presence of anti-dynorphin antiserum was significantly lower than the evoked CGRP release observed in tissues taken from morphine-pelleted rats in the absence or presence of control serum $(p \leq 0.05)$ and not significantly different from that observed in placebo-pelleted tissues in the absence or presence of control serum (Fig. 5A,B). For comparison purposes, evoked CGRP release in placebo-pelleted tissues was normalized as $100 \pm 15 \%$. Evoked CGRP release in morphine-pelleted tissues was found to be $197 \pm 26 \%$ of this control group $(p \leq 0.05)$. Similarly, evoked CGRP release in tissues taken from placebo-pelleted rats in the presence of control serum was normalized as $100 \pm 12 \%$. Evoked CGRP release in the presence of control serum in tissues taken from morphinepelleted rats was $182 \pm 12 \%(p \leq 0.05)$. Evoked CGRP release in the presence of dynorphin antiserum in tissues from placebopelleted rats was normalized as $100 \pm 17 \%$. Evoked CGRP release in the presence of anti-dynorphin antiserum in tissues from morphine-pelleted rats was found to be $102 \pm 22 \%$ of control, a value that was not significantly different.

\section{Dynorphin $A_{(2-13)}$, a non-opioid dynorphin fragment, enhances capsaicin-evoked released CGRP in naive tissue}

The possibility that pharmacological application of dynorphin $A_{(2-13)}$ might mimic the apparent facilitatory effects of upregulated endogenous spinal dynorphin elicited by sustained morphine treatment was tested. Basal and capsaicin-evoked CGRP release from spinal tissues harvested from naive rats was measured in the absence and presence of dynorphin $\mathrm{A}_{(2-13)}$. Dynorphin $\mathrm{A}_{(2-13)}(1 \mu \mathrm{M})$ applied to the superfusate in the absence of capsaicin did not evoke significant release of CGRP above the basal value (data not shown). In contrast, application of dynorphin $\mathrm{A}_{(2-13)}\left(\begin{array}{ll}1 & \mu \mathrm{M})\end{array}\right)$ significantly enhanced capsaicin-evoked CGRP release (Fig. 6A,B). For comparison, the mean evoked release of CGRP by $1 \mu \mathrm{M}$ capsaicin was normalized to $100 \pm$ $18 \%$. Superfusion of capsaicin with dynorphin $\mathrm{A}_{(2-13)}$ resulted in an evoked CGRP release of $336 \pm 96 \%(p \leq 0.05)$ of this control group (Fig. 6).

\section{DISCUSSION}

The results of the present study demonstrate the remarkable plasticity induced in the nervous system after sustained exposure to morphine. The present data confirm and extend previous 


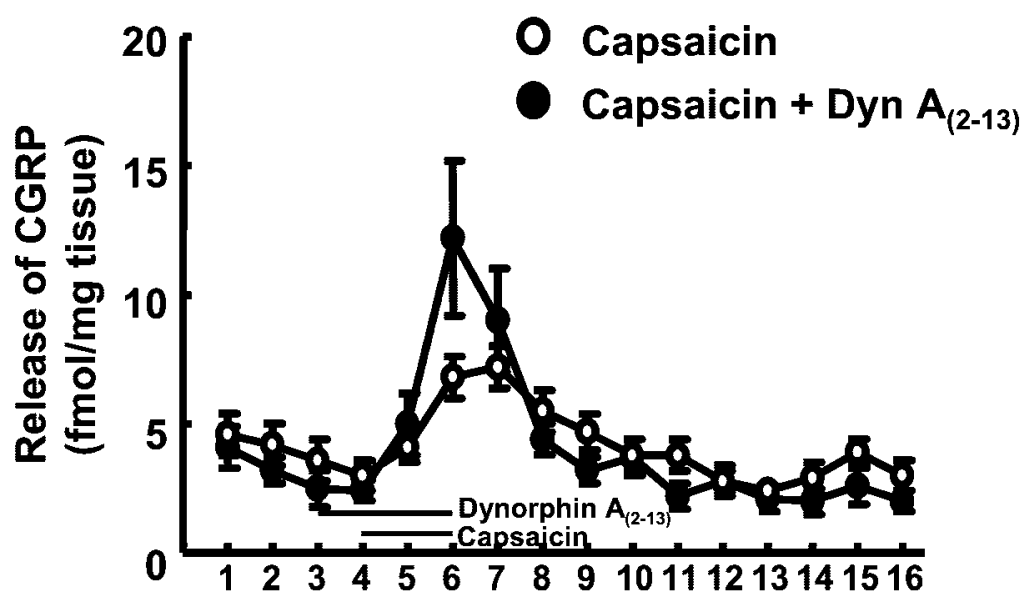

Fraction number ( 3 min intervals)

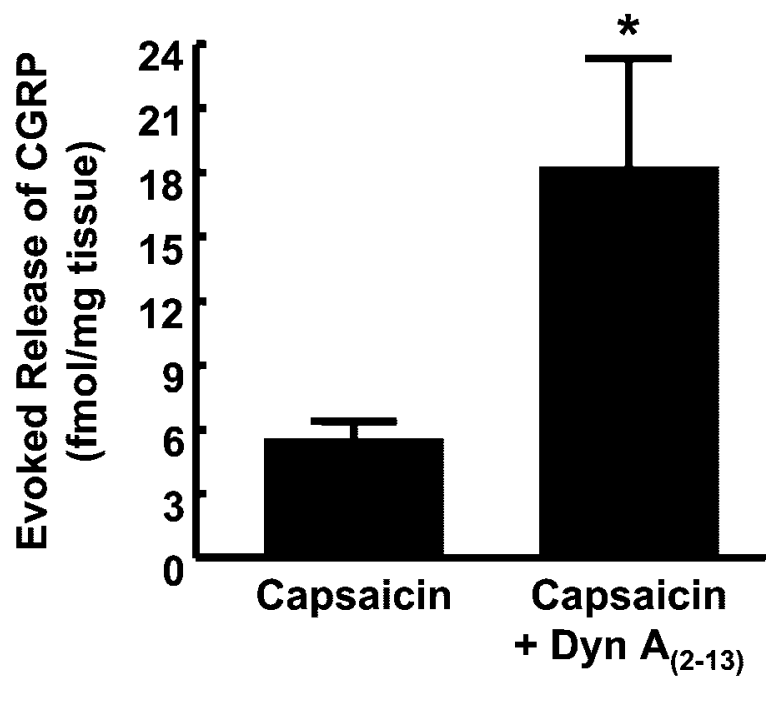

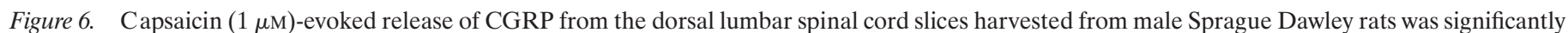

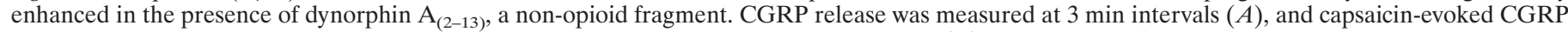

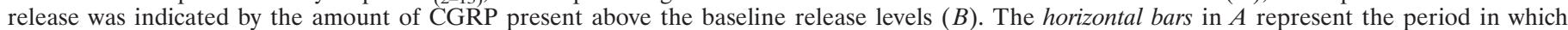

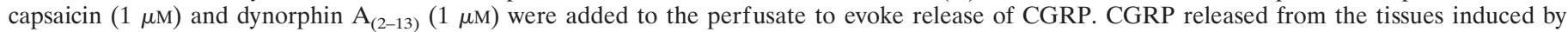

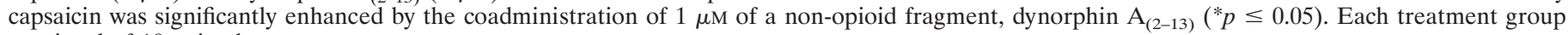
consisted of 10 animals.

findings indicating that morphine exposure significantly upregulates spinal dynorphin (Vanderah et al., 2000) and CGRP in vivo (Menard et al., 1996; Powell et al., 2000) and in vitro (Ma et al., 2000, 2001). The increase in expression of these substances appears to be of functional significance, providing a physiological basis for increased stimulus-induced excitation to the spinal cord that may underlie paradoxical opioid-induced pain. Several novel insights can be gleaned from these data that impact our understanding of opioid-induced paradoxical pain and possibly the behavioral manifestation of antinociceptive tolerance. First, the enhanced expression of spinal dynorphin produced by sustained morphine exposure requires descending influences via the DLF. Second, sustained morphine exposure results in enhanced content and evoked release of CGRP. Third, pharmacological application of non-opioid fragments of dynorphin enhance capsaicin-evoked release of CGRP, confirming the observations of Hargreaves and colleagues (Claude et al., 1999) and providing a possible basis for the increased evoked CGRP release measured in tissues from morphine-pelleted rats. Fourth, the increase in evoked CGRP release from spinal tissues taken from morphine-exposed rats is blocked by antiserum to dynorphin but not by a control serum, implicating endogenous dynorphin in this effect. Finally, manipulations that block the upregulation of spinal dynorphin resulting from morphine pellets, namely bilateral DLF lesions, also block the enhanced evoked CGRP release observed in tissues taken from morphine-pelleted rats. Together, these data support the hypothesis that morphine-induced upregulation of spinal dynorphin results secondary to plasticity in the RVM and that dynorphin acts in a non-opioid manner to enhance the evoked release of excitatory transmitters from primary afferent fibers. Because DLF lesions and dynorphin antiserum are manipulations that have been also been shown to block opioid-induced pain and antinociceptive tolerance (Vanderah et al., 2000, 2001b), it seems reasonable to suggest that enhanced evoked excitatory transmit- ter release may be an important factor that underlies opioidinduced paradoxical pain and the subsequent expression of antinociceptive tolerance.

The supraspinally mediated facilitation of nociceptive inputs at the level of the spinal cord is well recognized (Fields, 1992; Z huo and Gebhart, 1992; Urban et al., 1996; Urban and Gebhart, 1997; Porreca et al., 2002). Based on observations with microinjection of lidocaine and lesions of the DLF, an exaggerated persistence of such tonically active descending facilitation from the RVM has been suggested to be critical for the expression of morphineinduced paradoxical pain and antinociceptive tolerance (Tortorici et al., 2001; Vanderah et al., 2001a,b). Spinopetal projections from the RVM are known to descend through the DLF (Fields and Basbaum, 1999), suggesting the possibility that such descending influences may elicit changes at the spinal level. Although descending facilitation may promote nociceptive inputs directly, such influences may also promote pain indirectly, perhaps by invoking the upregulation of pronociceptive substances, such as dynorphin, in the spinal cord (Ossipov et al., 2001; Vanderah et al., 2001a). Studies have demonstrated repeatedly that persistent exposure to morphine strongly upregulates spinal dynorphin content (Nylander et al., 1995; Rattan and Tejwani, 1997; Vanderah et al., 2000, 2001a; Gardell et al., 2001). The present study extends these previous observations by demonstrating the regulatory influences of descending projections as disruption of the DLF blocks opioid-induced upregulation of spinal dynorphin. Importantly, lesions of the DLF also prevents the development of enhanced capsaicin-evoked release of CGRP observed in spinal tissues taken from morphine-treated rats. It therefore appears that the neuroplasticity of the RVM that has been suggested to result in descending facilitation also elicits the upregulation of spinal dynorphin and subsequently increases evoked neurotransmitter release, suggesting a strong functional 
link among these three phenomena and ultimately the behavioral consequences of morphine exposure.

The role of spinal dynorphin as a possible mediator of pain resulting from sustained morphine exposure is also supported by these, and previous, findings. Mice with deletions of the gene coding for prodynorphin fail to develop antinociceptive tolerance or behavioral signs of abnormal pain in response to morphine pellet implantation (Gardell et al., 2001). Furthermore, the spinal injection of MK-801 or of antiserum to dynorphin blocked enhanced pain and antinociceptive tolerance in the wild-type littermates (Gardell et al., 2001), as well as in morphine-exposed rats (Vanderah et al., 2000). Despite these observations, the precise mechanisms by which spinal dynorphin might mediate these effects have not been clear. Evidence for an excitatory action of spinal dynorphin has been supported by the observation of pharmacologically induced pain (Vanderah et al., 1996; Laughlin et al., 1997) and by observations demonstrating that pharmacological dynorphin $\mathrm{A}_{(1-13)}$ evoked an increased release of glutamate and aspartate into the extracellular fluid of the spinal cord (Skilling et al., 1992). These dynorphin effects were blocked by MK801, suggesting an NMDA-receptor mediated action (Skilling et al., 1992; Vanderah et al., 1996; Laughlin et al., 1997). Furthermore, infusion of dynorphin $\mathrm{A}_{(1-17)}$ and the des-Tyr derivative dynorphin $A_{(2-17)}$, which is devoid of binding affinity to opioid receptors, into hippocampal tissue through a microdialysis probe produced dose-dependent release of glutamate and aspartate, and this effect was not blocked by opioid antagonists (Faden, 1992). Dynorphin $\mathrm{A}_{(1-17)}$ potentiates the capsaicin-evoked release of substance P (SP) from caudal trigeminal nuclear slices, and this effect was not blocked by $\mu$-, $\delta$-, or $\kappa$-opioid receptor antagonists but was blocked by NMDA antagonists (Arcaya et al., 1999). Furthermore, neonatal capsaicin, which selectively destroys SPcontaining primary afferents, blocked the ability of dynorphin to facilitate $\mathrm{K}^{+}$-evoked release of SP in trigeminal slices (Arcaya et al., 1999). It was concluded that dynorphin enhances the release of SP from primary afferent C-fibers through an NMDA-related mechanism to promote exaggerated pain (Arcaya et al., 1999). Hargreaves and colleagues have demonstrated recently enhanced capsaicin-evoked release of CGRP by dynorphin $\mathrm{A}_{(2-13)}$ from naive rat spinal cord sections (Claude et al., 1999). This observation was confirmed in the present investigation and extended to encompass the role of endogenous dynorphin upregulated in the spinal cord after morphine treatment.

A possible basis for the enhanced evoked release of CGRP seen in tissues from morphine-exposed rats is the increased content of CGRP evident in both the spinal cord and the dorsal root ganglia. Increased spinal CGRP appeared to extend into deeper laminas of the spinal dorsal horn after morphine treatment. The reasons for this are not clear. Preliminary evidence suggests that the apparent number of CGRP-positive cells in the dorsal root ganglion is increased after morphine treatment. However, the nature of these cells (i.e., size and phenotype) awaits further characterization. Dynorphin can pharmacologically enhance the evoked release of CGRP from naive tissue, suggesting that upregulated content is not necessary. It is not clear whether the enhanced evoked release of CGRP seen in tissues from morphine-exposed rats, in which there is enhanced expression of endogenous dynorphin, results from the actions of dynorphin alone or depends also on the upregulation of CGRP. Nevertheless, the critical importance of spinal dynorphin is supported by the blockade of enhanced evoked release in morphine-exposed tissues by antidynorphin antiserum. Anti-dynorphin antiserum did not block evoked CGRP release in naive or placebo-pelleted tissues. Additionally, no enhanced evoked CGRP release was observed in tissues taken from morphine-exposed animals with previous lesions of the DLF. DLF or sham lesion did not alter evoked CGRP release in placebo-pelleted rats. This finding also demonstrates that the increased release of CGRP seen in tissues from morphine-exposed rats was not the result of an in vitro expression of opioid withdrawal. This conclusion is supported by the fact that tissues taken from rats with previous DLF lesions had been exposed to morphine in exactly the same way as those without DLF lesion. Also supporting this conclusion is the failure to demonstrate differences in basal (i.e., unstimulated) CGRP release in tissues from morphine- or placebo-pelleted rats. The latter observation also argues against possible "sensitization" of the release mechanisms in the afferent fibers after morphine treatment.

The molecular mechanisms by which dynorphin or its nonopioid fragments may enhance evoked release from primary afferents remain to be elucidated (for review, see Lai et al., 2001; Vanderah et al., 2001a). However, the actions of dynorphin, upregulated after sustained opioid exposure, appear to promote excitation, abnormal pain, and antinociceptive tolerance. Blockade of dynorphin actions or expression has been shown to block opioid abnormal pain and antinociceptive tolerance. In this regard, these findings are consistent with most of the actions of many other classes of substances that have been reported to block opioid antinociceptive tolerance. These substances most commonly block endogenous substrates that promote excitation and pain (for review, see Vanderah et al., 2001). Because pain can be regarded as a "physiological antagonist" of opioid antinociception, the present findings provide at least one possible basis for increased pain after sustained exposure to opioids and may allow new approaches for preventing the expression of opioid antinociceptive tolerance.

\section{REFERENCES}

Ali NM (1986) Hyperalgesic response in a patient receiving high concentrations of spinal morphine. Anesthesiology 65:449.

Arcaya JL, Cano G, Gomez G, Maixner W, Suarez-Roca H (1999) Dynorphin A increases substance $\mathrm{P}$ release from trigeminal primary afferent C-fibers. Eur J Pharmacol 366:27-34.

Arner S, Meyerson BA (1988) Lack of analgesic effect of opioids on neuropathic and idiopathic forms of pain. Pain 33:11-23.

Bederson JB, Fields HL, Barbaro NM (1990) Hyperalgesia during naloxone-precipitated withdrawal from morphine is associated with increased on-cell activity in the rostral ventromedial medulla. Somatosens Mot Res 7:185-203.

Burgess SE, Gardell LR, Ossipov MH, Malan Jr TP, Vanderah TW, Lai J, Porreca F (2002) Time-dependent descending facilitation from the rostral ventromedial medulla maintains, but does not initiate, neuropathic pain. J Neurosci 22:5129-5136.

Celerier E, Laulin J, Larcher A, Le Moal M, Simonnet G (1999) Evidence for opiate-activated NMDA processes masking opiate analgesia in rats. Brain Res 847:18-25.

Celerier E, Rivat C, Jun Y, Laulin JP, Larcher A, Reynier P, Simonnet G (2000) Long-lasting hyperalgesia induced by fentanyl in rats: preventive effect of ketamine. Anesthesiology 92:465-472.

Celerier E, Laulin JP, Corcuff JB, Le Moal M, Simonnet G (2001) Progressive enhancement of delayed hyperalgesia induced by repeated heroin administration: a sensitization process. J Neurosci 21:4074-4080.

Chaplan SR, Bach FW, Pogrel JW, Chung JM, Yaksh TL (1994) Quantitative assessment of tactile allodynia in the rat paw. J Neurosci Methods 53:55-63.

Claude P, Gracia N, Wagner L, Hargreaves KM (1999) Effect of dynorphin on ICGRP release from capsaicin-sensitive fibers. Abstracts of the 9th World Congress on Pain 9:262.

De Conno F, Caraceni A, Martini C, Spoldi E, Salvetti M, Ventafridda V (1991) Hyperalgesia and myoclonus with intrathecal infusion of highdose morphine. Pain 47:337-339.

Devulder J (1997) Hyperalgesia induced by high-dose intrathecal sufentanil in neuropathic pain. J Neurosurg Anesthesiol 9:146-148. 
Dixon WJ (1980) Efficient analysis of experimental observations. Annu Rev Pharmacol Toxicol 20:441-462.

Faden AI (1992) Dynorphin increases extracellular levels of excitatory amino acids in the brain through a non-opioid mechanism. J Neurosci 12:425-429.

Fields HL (1992) Is there a facilitating component to central pain modulation? Am Pain Soc J 1:71-78.

Fields HL, Basbaum AI (1999) Central nervous system mechanisms of pain modulation. In: Textbook of pain, Ed 4 (Wall PD, Melzack R, eds), pp 309-329. Edinburgh: Churchill Livingstone.

Gardell LR, Wang Z, Ossipov MH, Malan Jr TP, Lai J, Porreca F (2001) Lack of opioid tolerance in prodynorphin "knock-out" mice. Soc Neurosci Abstr 27:616.8.

Hargreaves K, Dubner R, Brown F, Flores C, Joris J (1988) A new and sensitive method for measuring thermal nociception in cutaneous hyperalgesia. Pain 32:77-88.

Heinricher MM, Barbaro NM, Fields HL (1989) Putative nociceptive modulating neurons in the rostral ventromedial medulla of the rat: firing of on- and off-cells is related to nociceptive responsiveness. Somatosens Motor Res 6:427-439.

Kaplan H, Fields HL (1991) Hyperalgesia during acute opioid abstinence: evidence for a nociceptive facilitating function of the rostral ventromedial medulla. J Neurosci 11:1433-1439.

Kim DH, Fields HL, Barbaro NM (1990) Morphine analgesia and acute physical dependence: rapid onset of two opposing, dose-related processes. Brain Res 516:37-40.

Kovelowski CJ, Ossipov MH, Sun H, Lai J, Malan TP, Porreca F (2000) Supraspinal cholecystokinin may drive tonic descending facilitation mechanisms to maintain neuropathic pain in the rat. Pain 87:265-273.

Lai J, Ossipov MH, Vanderah TW, Malan Jr TP, Porreca F (2001) Neuropathic pain: the paradox of dynorphin. Mol Interven 1:160-167.

Larcher A, Laulin JP, Celerier E, Le Moal M, Simonnet G (1998) Acute tolerance associated with a single opiate administration: involvement of $N$-methyl-D-aspartate-dependent pain facilitatory systems. Neuroscience 84:583-589.

Laughlin TM, Vanderah TW, Lashbrook J, Nichols ML, Ossipov M, Porreca F, Wilcox GL (1997) Spinally administered dynorphin A produces long-lasting allodynia: involvement of NMDA but not opioid receptors. Pain 72:253-260.

Laulin JP, Celerier E, Larcher A, Le Moal M, Simonnet G (1999) Opiate tolerance to daily heroin administration: an apparent phenomenon associated with enhanced pain sensitivity. Neuroscience 89:631-636.

Ma W, Zheng WH, Kar S, Quirion R (2000) Morphine treatment induced calcitonin gene-related peptide and substance $\mathrm{P}$ increases in cultured dorsal root ganglion neurons. Neuroscience 99:529-539.

Ma W, Zheng WH, Powell K, Jhamandas K, Quirion R (2001) Chronic morphine exposure increases the phosphorylation of MAP kinases and the transcription factor CREB in dorsal root ganglion neurons: an in vitro and in vivo study. Eur J Neurosci 14:1091-1104.

Mansikka H, Pertovaara A (1997) Supraspinal influence on hindlimb withdrawal thresholds and mustard oil-induced secondary allodynia in rats. Brain Res Bull 42:359-365.

Mao J, Price DD, Mayer DJ (1994) Thermal hyperalgesia in association with the development of morphine tolerance in rats: roles of excitatory amino acid receptors and protein kinase C. J Neurosci 14:2301-2312.

Mao J, Price DD, Mayer DJ (1995a) Mechanisms of hyperalgesia and morphine tolerance: a current view of their possible interactions. Pain 62:259-274.

Mao J, Price DD, Mayer DJ (1995b) Experimental mononeuropathy reduces the antinociceptive effects of morphine: implications for common intracellular mechanisms involved in morphine tolerance and neuropathic pain. Pain 61:353-364.

Mao J, Price DD, Phillips LL, Lu J, Mayer DJ (1995c) Increases in protein kinase $\mathrm{C}$ gamma immunoreactivity in the spinal cord of rats associated with tolerance to the analgesic effects of morphine. Brain Res 677:257-267.

Mao J, Price DD, Phillips LL, Lu J, Mayer DJ (1995d) Increases in protein kinase $\mathrm{C}$ gamma immunoreactivity in the spinal cord dorsal horn of rats with painful mononeuropathy. Neurosci Lett 198:75-78.

Mao J, Price DD, Lu J, Mayer DJ (1998) Antinociceptive tolerance to the mu-opioid agonist DAMGO is dose-dependently reduced by $\mathrm{MK}$ 801 in rats. Neurosci Lett 250:193-196.

Menard DP, van Rossum D, Kar S, St. Pierre S, Sutak M, Jhamandas K, Quirion R (1996) A calcitonin gene-related peptide receptor antagonist prevents the development of tolerance to spinal morphine analgesia. J Neurosci 16:2342-2351.

Morgan MM, Heinricher MM, Fields HL (1992) Circuitry linking opioid-sensitive nociceptive modulatory systems in periaqueductal gray and spinal cord with rostral ventromedial medulla. Neuroscience 47:863-871.

Nylander I, Vlaskovska M, Terenius L (1995) The effects of morphine treatment and morphine withdrawal on the dynorphin and enkephalin systems in Sprague-Dawley rats. Psychopharmacology 118:391-400.

Ossipov MH, Lai J, Malan Jr TP, Vanderah TW, Porreca F (2001) Tonic descending facilitation as a mechanism of neuropathic pain. In: Neuropatic pain: pathophysiology and treatment (Hansson PT, Fields HL Hill RG, Marchettini P, eds), pp 107-124. Seattle: International Association for the Study of Pain.

Porreca F, Ossipov MH, Gebhart GF (2002) Medullary descending facilitation may drive chronic pain. Trends Neurosci 25:319-325.

Powell KJ, Ma W, Sutak M, Doods H, Quirion R, Jhamandas K (2000) Blockade and reversal of spinal morphine tolerance by peptide and non-peptide calcitonin gene-related peptide receptor antagonists. $\mathrm{Br} \mathrm{J}$ Pharmacol 131:875-884.

Rattan AK, Tejwani GA (1997) Effect of chronic treatment with morphine, midazolam and both together on dynorphin(1-13) levels in the rat. Brain Res 754:239-244.

Skilling SR, Sun X, Kurtz HJ, Larson AA (1992) Selective potentiation of NMDA-induced activity and release of excitatory amino acids by dynorphin: possible roles in paralysis and neurotoxicity. Brain Res 575:272-278.

Stillman MJ, Moulin DE, Foley KM (1987) Paradoxical pain following high-dose spinal morphine. Pain 4:S389.

Tortorici V, Morgan MM, Vanegas H (2001) Tolerance to repeated microinjection of morphine into the periaqueductal gray is associated with changes in the behavior of off- and on-cells in the rostral ventromedial medulla of rats. Pain 89:237-244.

Urban MO, Gebhart GF (1997) Characterization of biphasic modulation of spinal nociceptive transmission by neurotensin in the rat rostral ventromedial medulla. J Neurophysiol 78:1550-1562.

Urban MO, Smith DJ, Gebhart GF (1996) Involvement of spinal cholecystokininB receptors in mediating neurotensin hyperalgesia from the medullary nucleus raphe magnus in the rat. J Pharmacol Exp Ther 278:90-96.

Vanderah TW, Laughlin T, Lashbrook JM, Nichols ML, Wilcox GL, Ossipov MH, Malan Jr TP, Porreca F (1996) Single intrathecal injections of dynorphin A or des-Tyr-dynorphins produce long-lasting allodynia in rats: blockade by M K-801 but not naloxone. Pain 68:275-281.

Vanderah TW, Gardell LR, Burgess SE, Ibrahim M, Dogrul A, Zhong CM, Zhang ET, Malan Jr TP, Ossipov MH, Lai J, Porreca F (2000) Dynorphin promotes abnormal pain and spinal opioid antinociceptive tolerance. J Neurosci 20:7074-7079.

Vanderah TW, Ossipov MH, Lai J, Malan TP, Porreca F (2001a) Mechanisms of opioid-induced pain and antinociceptive tolerance: descending facilitation and spinal dynorphin. Pain 92:5-9.

Vanderah TW, Suenaga NM, Ossipov MH, Malan Jr TP, Lai J, Porreca F (2001b) Tonic descending facilitation from the rostral ventromedia medulla mediates opioid-induced abnormal pain and antinociceptive tolerance. J Neurosci 21:279-286.

Yaksh TL, Harty GJ (1988) Pharmacology of the allodynia in rats evoked by high dose intrathecal morphine. J Pharmacol Exp Ther 244:501-507.

Yaksh TL, Harty GJ, Onofrio BM (1986) High dose of spinal morphine produce a nonopiate receptor-mediated hyperesthesia: clinical and theoretic implications. Anesthesiology 64:590-597.

Zhuo M, Gebhart GF (1992) Characterization of descending facilitation and inhibition of spinal nociceptive transmission from the nuclei reticularis gigantocellularis and gigantocellularis pars alpha in the rat. J Neurophysiol 67:1599-1614. 